\title{
An Exploration of Real-World Analogical Problem Solving in Novices
}

\author{
Christopher R. Bearman (c.bearman@lancaster.ac.uk) \\ Department of Psychology, Fylde College, Lancaster University, \\ LA14YD, UK \\ Linden J. Ball (l.ball@lancaster.ac.uk) \\ Department of Psychology, Fylde College, Lancaster University, \\ LA14YD, UK \\ Thomas C. Ormerod (t.ormerod@lancaster.ac.uk) \\ Department of Psychology, Fylde College, Lancaster University, \\ LA14YD, UK
}

\begin{abstract}
Despite the postulated importance of analogising to human cognition, the study of analogical problem solving in the laboratory has found disappointing results. Providing an analogue to a participant prior to asking them to solve a problem gives only a small benefit at best. Recently, studies outside the laboratory have suggested that experts frequently use analogies in realworld situations. It is less clear whether novices can also spontaneously invoke and use analogies to solve realistic problems. In the current investigation, undergraduates were observed solving a large-scale management problem over two weeks. It was found that many analogies were produced (on average 4.6 per one-hour session), and that $77 \%$ of these analogies reflected a structural rather than a superficial mapping between a base and a target. It was also determined that $56 \%$ of these structural analogies involved non-trivial mappings of higher-order relations. Further, it was found that analogies were drawn to serve two different purposes: problem solving and illustration. In generating illustrative analogies, participants frequently made superficial mappings, but when generating analogies to solve problems, they never made purely superficial mappings.
\end{abstract}

Analogy is defined by the Oxford English Dictionary as the "resemblance of relations or attributes as a ground of reasoning." The ability to draw analogies is considered to be fundamental to intelligent human behaviour (Holyoak \& Thagard, 1995). Analogy appears to be central to both the processing of information and its retrieval from long-term memory (Shank, 1999) and underpins theories of creative thinking and intelligence (Holyoak \& Thagard, 1995; Poze, 1983; Raven, 1938; Sternberg, 1977).

The postulated importance of analogising for intelligent human behaviour stands in contrast to the findings from laboratory studies of analogical problem solving. It is often found that providing a superficially dissimilar but structurally analogous source to a participant prior to them solving a target problem, without a hint about either its relevance or relatedness to the target, gives little or no gain in target solution rates (Anoli, Antonietti, Crisafulli \& Cantoia, 2001; Gick \& Holyoak, 1980, 1983).

Transfer of the analogous solution without a hint is not improved by: providing a static diagrammatic representation of the structural analogue (Gick \& Holyoak, 1983; Podone, Hummel \& Holyoak, 2001); providing an abstract verbal statement of the underlying structural analogue (Gick \& Holyoak, 1983); or simply re-presenting the source to the participant while they are processing the target (Anoli et al., 2001; Gick \& Holyoak, 1980). There is some evidence of analogical transfer when multiple analogous sources are provided (Catrambone \& Holyoak, 1989; Gick \& Holyoak, 1983), and also when the analogous source is a general concept (Schunn \& Dunbar, 1996). Generally, however, the findings from laboratory-based studies of analogy have been disappointing.

Recently, analogy has begun to be investigated in applied as well as experimental contexts. This research has particularly focused on the behaviour of experts. For example, Hargadon (1999) describes how 'knowledge brokers' in management draw comparisons between different areas in order to move ideas from where they are known to where they are not. Marchant, Robinson, Anderson and Schadewald (1993) investigated the use of analogies in the interpretation of tax statutes in graduate students and professional lawyers. They found that both groups demonstrated high rates of transfer from a structural analogue. Dunbar and Blanchette (2001; Dunbar, 2001) have documented the use of analogy by immunologists and molecular biologists, finding that structural analogising was particularly prevalent when the scientist was engaged in theory building. Dunbar and Blanchette (2001) were also able to determine the function of the analogies in their observations. When isolated 
unexpected results occurred the scientists drew analogies to similar experiments, what Dunbar and Blanchette (2001) call local analogies. However, when a series of unexpected results occurred the scientists drew more distant analogies to the function of similar components in other organisms. The type of mapping appears to differ depending on the purpose for which it is drawn.

Thus, it appears that experts in applied settings are able to draw analogies between base and target problems. This is consistent with the widely held view that differences between experts and novices reflect different representational levels of information encoding. Experts are able to encode information at a deeper, structural level, while novices generally only encode information at a surface or superficial level (Chi, Feltovich \& Glaser, 1981; Klein, 1999; Novick, 1988). Consistent with this explanation is a study by Thompson, Gentner and Loewenstein (2000), which found that unless management students were actively encouraged to compare source analogues in order to draw out structural relations, then rates of transfer of an underlying concept were low.

There is some evidence, however, that novices can also make use of structural analogies without being encouraged to create structural mappings. Blanchette and Dunbar (2000, 2001; Dunbar, 2001) found that novices were able to draw structural inferences when reasoning using metaphors. In a study where participants had to explain a concept to another person using a metaphor, it was found that the metaphor was frequently chosen from a domain outside the one being explained, suggesting that cross-structural mapping was occurring. One of the important aspects of Blanchette and Dunbar's study may be that participants were able to draw on any area of their knowledge in creating the analogies. This is in contrast to the previous studies involving novices that have examined the ability to produce a specific analogical mapping. Thus, it may be that novices are able to use analogy effectively if they are allowed to draw on memory more generally.

Metaphors are, however, slightly different from the types of analogies drawn to solve problems. Although metaphor relies upon the mechanism of analogy it is different from the kinds of analogy used in problem solving in two key respects. First, the relationship between source and target is different. In using analogy to solve problems the person must find a source that informs a less well understood target, whilst in drawing a metaphor a person has a target and must generate a source that explicates the underlying topic (Holyoak \& Thagard, 1995). Second, metaphors often depend upon a combination with metonymy (where ideas substitute for each other) and the pattern of relations often shifts because of this in a way that problem solving analogies rarely do (Holyoak \& Thagard, 1995).
The present study was, therefore, designed to extend existing research by addressing the question of whether novices can spontaneously make analogical mappings in order to solve management problems if they are allowed to draw more widely on stored knowledge. Also, in light of Blanchette and Dunbar's (2001) observations concerning the differing functions of analogies in real-world situations, we were alert to the possibility that management contexts might similarly be associated with analogy use aimed at achieving different functions.

\section{Method}

The study investigated undergraduate students in Management conducting an analysis of a 'business case' as part of a 'case method' course, a teaching method designed to simulate real-life management decisionmaking (Easton, 1992). Participants worked in groups and were required to specify the problems and opportunities inherent in the case, and to produce a set of solutions that might optimise the business described in the case. The task may be described as ill-defined (Van Lehn, 1989) and in some respects, un-defined. No restrictions were placed on the knowledge sources that participants might employ during the case analysis. No source analogues were presented to participants, and the concept of analogy was not mentioned to them as part of the course or the investigation.

\section{Materials}

The cases consisted of descriptions of a business or industry facing a loosely defined threat or opportunity. The business cases were chosen for their pedagogical merit by the assessing tutor and consisted of three different situations that described the position of a business or industry. The cases were 'The Champagne Industry in 1993' (Cool, Howe \& Henderson, 1994), 'Petrol Retailing in Europe: The UK Market' (Levy, 1999), and 'Delta Dairies' (Easton \& Dritsas, 1992). The cases were 19, 13 and 11 pages long, respectively, and are available from the European Case Clearing House Collection (http://www.ecch.cranfield.ac.uk.).

\section{Participants}

The participants were 24 final year undergraduate students from Lancaster University. The outcomes of each group's analysis was examined by a tutor as part of the student's course assessment. Participants were not paid.

\section{Procedure}

Six groups of four people were formed on the basis of who would and wouldn't work well with each other by the assessing tutor. Each group examined a single case with each case being analysed twice by two separate 
groups. The groups spent two weeks conducting an analysis of their case. During this period the groups met both on their own and with the tutor. The groups met with the tutor between three and four times for approximately an hour. It is data from these sessions that were used for the present investigation. At the end of the analysis period the groups were required to make a 20 minute presentation to their peers, in the form of recommendations for the business.

\section{Results}

19 tutorials (out a possible 22) were observed and audio-taped. Instances of analogising in the tutorials were transcribed from the audio-tapes (off-task analogies were excluded). For the purposes of this study, analogy was considered to have occurred when reference was made to an episode of prior experience (a base) and was applied to a current idea in some way (a target). The extract was excluded when the base was drawn from lectures, the assessing tutor or directly from the case. The application of management knowledge or general knowledge was not considered to be an analogy in this study. A 15\% sample of these tapes was recoded by a second coder, and any discrepancies in analogy extraction were discussed until consensus was reached. Over the 19 tutorials there were 86 occasions when an analogy was made, a mean of 4.5 analogies per hour-long tutorial (standard deviation $=4.98$, range $=0$ 20) and only one tutorial contained no discernible analogising.

\section{Structure of the Analogies}

The extracts of analogies were sorted into three categories based on a form of predicate calculus similar to that used by Gentner (1983). Extracts were defined in terms of whether the mapping between the base and the target involved merely superficial attributes, a firstorder relation, or a complex systemic relation. An extract was classed as superficial if the mapping was in terms of objects only, with no discernible structural mapping. A simple, first-order relational mapping occurred when a simple relation that held in the source was also observed to hold in the target. A complex mapping of systems of relations occurred when higherorder relations were seen to be mapped, such as causal relations or plot structure (cf. Gentner, 1983).

It was found that $43 \%$ of the analogies generated that included an explicit mention of a target and base situation involved mappings of higher-order relations, such as can be seen in the following extract:

P1: "The marketing option, as well, which we'll use on the short-term; have you seen the BP advert?

CL: Yes.
P1: We're going down that line. We were saying so the other day. The amount at which it burns cleaner is negligible, but perceptions - so go for a cleaner image in the way BP are doing now. They're playing on the fact that that pollution is becoming more and more evident. Everybody is starting to understand it now, accept it, rather than just saying, 'it's rubbish that, we're not Greenpeace people'. It's becoming more of a factor in society against dirty polluting petrol. So, I mean, using the BP model, try to change people's perceptions about what your company at the moment, what the fuel is in [inaudible] it a greener alternative." [Group 4, $2^{\text {nd }}$ tutorial]

The analogical mapping from base and target that is apparent in this extract can be restated using a propositional formalism, as follows:

Cause [Cause [Becoming-more-evident(Pollution), Becoming-greener(Society)], Use-as-marketing-option (BP, Green-standpoint)] $\square$

Cause [Cause [Becoming-more-evident(Pollution), Becoming-greener(Society)], Use-as-marketing-option (Company-Y, Green-standpoint)]

The initial set of propositions capture the idea that the company in the base situation (British Petroleum) is taking a green standpoint because society is becoming greener in response to pollution becoming more evident. It is these systems of causal relations that this management group is mapping across to their own marketing option. It is noteworthy, too, that there are a number of higher-order relationships evident in the base situation, and the fact that these relations get mapped between base and target appears to demonstrate that novices can produce non-trivial analogies with sophisticated relational structures.

A further $34 \%$ of the analogies that involved the explicit mention of base and target situations involved first-order relational mappings. An example of such a mapping can be observed in the following extract:

P1: "That does happen though doesn't it, in supermarkets?

CL: What?

P1: That you could, it goes both - the exclusivity goes both ways but for huge brands, not the same size as ours. They state that a competitor can't be (sold in the supermarket)." [Group 2, 3 ${ }^{\text {rd }}$ tutorial]

This analogy can be represented propositionally as:

Has-exclusivity-deal-with(Huge-brand, Supermarket)

Has-exclusivity-deal-with(Company-Y, Supermarket) 
Here the group is thinking of copying the idea that they think is used by big companies of forcing a competitor off the shelves of a supermarket by signing an exclusivity deal.

Overall, then, $77 \%$ of the analogies produced by the novices observed in this study were based on structural mappings (either first-order relations or higher-order relations).

\section{Function of the Analogies}

The data were subjected to a thematic analysis in order to investigate further the type and function of the analogies employed by the management novices in this study. The emphasis in this analysis was on the solution or idea that emerged from the mapping, rather than on the nature of the mapping itself. In a thematic analysis extracts are grouped together based on their similarity, such that categories are developed based on common themes. Thematic analysis is a useful way of sorting qualitative data so that categories are allowed to emerge in a relatively atheoretical way (see Plummer, 1995; Smith, 1995). A second coder was able to recreate the themes identified with $88 \%$ accuracy (following a training session using $1 / 3$ of the data). This analysis indicated that analogies were appearing to serve two different functions: problem solving and illustration.

Problem-Solving Analogies Of these analogies, 23\% were direct base-to-target solutions, with both base and target present in the same extract. These took the form of 'x did y, so we can copy them'. For example:

"You could go on convenience a bit because there is an Esso station in Southampton, where I'm from, that is totally self-sufficient. It doesn't have anybody working there, and has, like, Coke dispensers, and all the kinds of food dispensers, and you pay at the pump and then you, you know, I've seen people pick up snacks from these machines and then they go. They're completely unmanned. That might be a possibility for convenience." [Group 3, $1^{\text {st }}$ tutorial]

This type of analogy may be represented propositionally as:

\section{Market-on-convenience(Esso-station,Fully-self-service) \\ Market-on-convenience(Company-Y,Fully-self-service)}

A further $15 \%$ of the analogies were elaborated baseto-target solutions. In these cases, a base was mapped to the target as in the direct base-to-target solutions, but the information gained from the analogy was used to form a new solution, rather than simply mapping the solution across wholesale from the base. For example:
"Another thing that we were having difficulty coming up with is an actual price, because we were thinking, 'Shall we out-price Moet et Chandon by only a small amount because it gives that exclusivity, and we didn't want to go for exactly the same price because we've got this unique selling point?' So if you just did it a tiny bit more expensive, going to that bit much it's as good as and it's got this unique selling point, and it's only a tiny bit more so that it's not too much of a stretch to buy it over Moet et Chandon. So people realise that it must be better, because it's that bit more expensive, and it's got this unique selling point." [Group 2, $2^{\text {nd }}$ tutorial].

This analogy and its associated solution development may be represented in propositional form as:

Analogy: Use-as-marketing-points (Moet-et-Chandon, Product-quality-and-product-exclusivity) and Indexedby (Product-quality, High-price)

Use-as-marketing-points (Company-Y, Product-qualityand-product-exclusivity) and Indexed-by (Productquality, High-price)

Solution idea: Cause [More-expensive-than (Company-

Y-one-press-champagne, Moet-et-Chandon-

champagne), Gain-market-advantage-over (Company-

Y, Moet-et-Chandon)]

An additional $35 \%$ of the analogies were sources that shaped the group's decision making but which lacked a target that was explicitly referenced in the extract itself. An example of this comes from Group 2, $2^{\text {nd }}$ tutorial:

"You know, like, how Safeway have got a grading system where, like, they've got bronze, silver and gold labelled wines, and things like that, you know, if they have something, I don't know what Casino have. But the supermarket's recommendation can be quite powerful. If you're looking for a wine in Safeway's and you don't particularly recognise the label, if you read the little Safeway bit on the back you know it's this level of sweetness, and it goes with this and that and the other. You're quite tempted to try some first time."

This extract shows that the group has taken the idea of the power of the supermarket's recommendation and this later guides the group's solution towards striking a deal with a French supermarket which leads to the recommendation of a dual-branding scheme, where the supermarket and the producer's name is on the bottle.

All of the analogies produced in order to serve a problem-solving purpose used either higher-order relational mappings or first-order relational mappings. There were no purely superficial mappings used to solve a problem. 
Illustrative Analogies Twenty-seven percent of the analogies were designed not to facilitate directly the generation of a new solution idea, but instead for the purpose of exemplifying or illustrating an existing idea. Such analogies, therefore, appeared to be metaphorical in nature and intent rather than directed at problem solving per se. In such cases, the participant generated a source to explicate the target. For example, a member of Group 4 ( $2^{\text {nd }}$ tutorial) drew parallels between the market positions of Coca Cola and Pepsi to illustrate the position faced by an oil company under consideration:

"You know, you said the other day that Coca Cola and Pepsi are within an arm's reach, - there's not much of a differentiation. It's the same here. It's just we've got more petrol stations and more people buying out of convenience."

The previous extracts concerned global target ideas of facilitating convenience at petrol stations, and the pricing for a new one-press champagne. In contrast, the illustration analogies lack these overarching ideas and extend no further than the base to target mapping. They are merely designed as a comparison of one idea with another.

In contrast to the analogies drawn to solve problems where there was no superficial mappings, when the analogy was drawn for illustrative purposes, $57 \%$ of the analogies were based on superficial mappings (with $26 \%$ based on higher-order mappings and $17 \%$ based on first-order relations).

When participants are solving problems it does not make any sense to map a superficially similar but structurally dissimilar source to a target, since this would not aid problem solving. In contrast, when an analogy is merely being used for illustrative purposes, it is possible simply to use a superficial mapping, since the purpose is merely to facilitate understanding rather than advance solution development.

\section{Discussion}

These results are important for two main reasons. First, by demonstrating spontaneous analogising by novice problem-solvers in a naturalistic domain, they corroborate the widely held view (e.g., Anderson, 2000; Holland, Holyoak, Nisbettt \& Thagard, 1986) that analogising plays a fundamental role in human problem-solving. Second, the emphasis on structural rather than superficial mappings demonstrates a sophistication in the manipulation of domain knowledge that is not usually associated with novices. It may be that, in some domains at least, novices are quite capable of recognising and manipulating information at a conceptual rather than superficial level.
Like the experts observed by Dunbar and Blanchette (2000), it was observed in this study that novices also drew analogies to serve different purposes, and that the nature of the mapping differs depending on this purpose. When solving problems, the novices used only first-order and higher-order relational mappings. However, when they were illustrating an idea, over half of the analogies were made using superficial mappings.

The analysis also highlighted a potentially important distinction between solutions that are simply mapped across from a source analogue, and solutions that are developed as a result of additional idea generation subsequent to the attainment of an analogical mapping. It may be that much of the skill in management problem solving is to extend and elaborate upon initial analogical mappings.

There are some important qualifications to our results. Perhaps the key one is that the data we report here reflect group tutorial activity in which a fair proportion of the exchanges consist of the communication of ideas and outcomes among participants. On the basis of these data alone, we cannot ascertain whether the role played by analogy is one of genuine problem-solving, or whether it serves a mainly communicative role, making ideas and solutions that have been discovered and worked through using other problem-solving strategies easier to share between individuals. In a sense, it does not affect the outcomes reported here, since either role is crucial in collaborative problem-solving. However, future studies that are not tutorial-based are needed to determine the precise function of novice analogising in this domain.

This investigation differs from experimental studies of analogy in the following key ways. First, analogies could be drawn from any area of a participant's experience, and sources were not provided by the experimenter. Second, participants solved the problems in groups rather than individually. Third, the participants had two weeks of discussion-based learning to analyse and solve the presented problem. It is clear that the method of exploring analogy use employed here and the standard experimental method represent very different paradigms, such that direct comparisons between the two should be drawn with caution. However, considering that experiments are supposed to be analogues of real-world situations in a simplified form, a reconsideration as to how analogical problem solving can fruitfully be investigated experimentally may need to be undertaken in light of the mounting evidence that people frequently make cross-structural analogies in the real-world.

\section{Acknowledgements}

This research was funded by an ESRC grant to the first and third authors, with co-funding from the European Case Clearing House. We are grateful to Geoff Easton 
for providing us with access to his students, and to Rosamund Ward who acted as the second coder for our coding-reliability checks.

\section{References}

Anderson, J. R. (2000). Learning and memory: An integrated approach. New York: Wiley.

Anoli, L., Antonietti, A., Crisafulli, L., \& Cantoia, M. (2001). Accessing source information in analogical problem-solving. Quarterly Journal of Experimental Psychology, 54A, 237-261.

Blanchette, I., \& Dunbar, K. (2000). How analogies are generated: The roles of structural and superficial similarity. Memory and Cognition, 28, 108-124.

Blanchette, I., \& Dunbar, K. (2001). Analogy use in naturalistic settings: The influence of audience, emotion, and goals. Memory and Cognition, 29, 730735.

Catrambone, R., \& Holyoak, K. J. (1989). Overcoming contextual limitations on problem-solving transfer. Journal of Experimental Psychology: Learning, Memory and Cognition, 15, 1147-1156.

Chi, M. T. H., Feltovich, P. J., \& Glaser, R. (1981). Categorization and representation of physics problems by experts and novices. Cognitive Science, $5,121-152$

Cool, K., Howe, J., \& Henderson, J. (1994). The champagne industry in 1993. European Case Clearing House Collection.

Dunbar, K. (2001). The analogy paradox: Why analogy is so easy in naturalistic settings, yet so difficult in the psychological laboratory. In D. Gentner, K. J. Holyoak, \& B. Kokinov (Eds.). Analogy: Perspectives from cognitive science. Cambridge, MA: MIT Press.

Dunbar, K., \& Blanchette, I. (2001). The in vivo/in vitro approach to cognition: the case of analogy. Trends in Cognitive Sciences, 5, 334-339.

Easton, G. (1992). Learning from case studies $\left(2^{\text {nd }}\right.$ Edn.). New York: Prentice Hall.

Easton, G., \& Dritsas, M. (1992). Delta Dairies. European Case Clearing House Collection.

Gentner, D. (1983). Structure-Mapping: A theoretical framework for analogy. Cognitive Psychology, 7, 155-170.

Gick, M. L., \& Holyoak, K. J. (1980). Analogical Problem Solving. Cognitive Psychology, 12, 306-355.

Gick, M. L., \& Holyoak, K. J. (1983). Schema induction and analogical transfer. Cognitive Psychology, 15, 1-38.

Halford, G. (1992). Analogical reasoning and conceptual complexity in cognitive development. Human Development, 35, 193-217.

Hargadon, A. B. (1999). The theory and practice of knowledge brokering: Case studies of continuous innovation. Dissertation Abstracts-International Section A: Humanities and Social Science, 59, 3075.

Holyoak, K. J., \& Thagard, P. (1995). Mental leaps: Analogy in creative thought. Cambridge, MA: MIT Press.

Holland, J. H., Holyoak, K. J., Nisbett, R. E., \& Thagard, P. R. (1986). Induction, Processes of inference, learning and discovery. Cambridge, MA: MIT Press.

Klein, G. (1999). Sources of power: How people make decisions. Cambridge, MA: MIT Press.

Levy, A. (1999). Petrol retailing in Europe: The UK market. European Case Clearing House Collection.

Marchant, G., Robinson, J., Anderson, U., \& Schadewald, M. (1993). The use of analogy in legal argument: Problem similarity, precedent and expertise. Organisational Behaviour and Human Decision Making Processes, 55, 95-119.

Novick, L. R. (1988). Analogical transfer, problem similarity and expertise. Journal of Experimental Psychology: Learning, Memory and Cognition, 14, 510-520

Pedone, R., Hummel, J. E., \& Holyoak, K. J. (2001). The use of diagrams in analogical problem solving. Memory and Cognition, 29, 214-221.

Poze, A. (1983). Analogical connections: The essence of creativity. Journal of Creative Behaviour, 17, 240258.

Plummer, K. (1995). Life story research. In J. A. Smith, R. Harre, \& L. V. Langenhoven, (Eds.), Rethinking methods in psychology. London: Sage

Raven, J. C. (1938). Progressive matrices: A perceptual test of intelligence. London: Lewis.

Schank, R. C. (1999). Dynamic memory revisited. Cambridge, UK: Cambridge University Press.

Schunn, C. D., \& Dunbar, K. (1996). Priming, analogy and awareness in complex reasoning. Memory and Cognition, 24, 271-284.

Smith, J. A. (1995). Semi-structured interviewing and qualitative analysis. In J. A. Smith, R. Harre, \& L. V. Langenhoven, (Eds.), Rethinking methods in psychology. London: Sage

Sternberg, R. J. (1977). Component processes in analogical reasoning. Psychological Review, 84, 353378.

Thompson, L., Gentner, D., \& Loewenstein, J. (2000). Avoiding missed opportunities in managerial life: Analogical training more powerful than individual case training. Organizational Behaviour and Human Decision processes, 82, 60-75.

VanLehn, K. (1989). Problem solving and cognitive skill acquisition. In M. I. Posner (Ed.), Foundations of cognitive science. Cambridge, MA: MIT Press. 